\title{
The COVID-19 Pandemic from an Adult Literacy Practitioner-Scholar Perspective: Where We Were, Where We Are, and Where We Should Be Going
}

Sasha V. Lotas, Academy of Hope Adult Public Charter School

In March 2020, Academy of Hope (AoH) Adult Public Charter School, an adult education and workforce development program in Washington, D.C., abruptly shifted - as did most schools in the nation - to a full distance learning model. This suddenness necessitated a huge teaching and learning cultural shift: In only one week, $\mathrm{AoH}$ transitioned from an in-classroom learning environment augmented by digital learning tools to a remote learning environment reliant on digital learning tools.

Almost a year later at the time of this writing, AoH is still navigating this shift, while also learning from and becoming catalyzed by it. I write this reflection as an adult literacy practitioner-scholar - one who was deeply involved in the sudden orchestration of "lockdown" virtual schooling for adults, as well as one who has struggled with negotiating the tension of conflicting paradigms in adult literacy education, such as the tension between a Freirianbased model and a workforce-readiness model (Demetrion, 2013). While this unprecedented pandemic-year has greatly challenged all fields of our educational system, it has especially challenged the adult literacy education field. Yet, it has also shed more light on the value of the field, as well as on the value of tolerating and learning from the field's tensions as it grows and evolves in both a pandemic and post-pandemic world (Roumell, 2021).

\section{Background}

Founded in 1985, Academy of Hope began as a small grassroots adult GED program. Over the next 29 years, AoH grew from two volunteers, four students, and four GED books, to serving more than 500 students annually with over 70 active volunteers. In addition to GED preparation, AoH subsequently added the National External Diploma Program (NEDP), technology training, career counseling, and workplace literacy.

In 2014, Academy of Hope became the eighth adult public charter school in the District of Columbia. (The District is rare in that it is home to over $10 \%$ of adult charter schools in the nation (Simpson-Baird, 2020).) The decision to evolve from a grassroots adult literacy program to an adult public charter school was fueled by 
the changing adult education landscape: both a revised common-core based GED exam and NEDP, as well as changes mandated by the statute that provides federal funds for adult education, the Workforce Innovation and Opportunity Act (WIOA) which superseded the Workforce Investment Act (WIA).

By becoming a charter school, AoH was better able to both prepare for adult education's demanding new role in the $21^{\text {st }}$ century knowledge economy, while also remaining committed to holistically serving adult learners. We hired professionally-trained teachers and enhanced the programming offered to our learners, including workforce training and college transitional services. At the same time, we were also able to invest in critical support services: After years of experience in the adult literacy education field, we recognized that literacy classes, alone, could not sufficiently address the inequitable societal and systemic barriers facing many of our learners.

\section{COVID-19 Pandemic: Building Infrastructure to Meet our Learners' Academic Needs}

Understanding that adult learners could not afford to put their education or career training on hold for the duration of the pandemic, our transition to distance learning was swift and expansive. We converted 44 in-person classes into both analog and digital remote classes in the spring of 2020, allowing us to continue serving both lower and higher-level ABE learners.

Our transition was also extremely challenging. Like many other adult literacy programs in the nation, one of our greatest challenges was learners' lack of access to devices and broadband (Belzer et al., 2020). When the COVID-19 crisis began in March, nearly 75\% of $\mathrm{AoH}$ learners reported they did not have the digital tools needed to fully participate in distance learning. Of those with devices, many relied on their cell phones to participate in virtual learning, and others shared devices with their children, who were simultaneously participating in their own virtual learning.

In addition, transferring classroom-based instruction to virtual instruction was complicated, as was navigating among various digital learning tools, causing staff and student frustration and some learner disengagement. We quickly understood that adult literacy virtual teaching and learning necessitates more than just teachers, learners, and technology; it also requires a robust behind-the-scenes infrastructure that connects and supports all three.

Fortunately, the summer break allowed us some time to better prepare for distance learning in the fall. With much fundraising and advocacy work, we were able to provide every learner with a Chromebook and internet access, and we were also able to offer technology bootcamps so that learners could receive intensive and individualized digital literacy support.

We also invested in a learning management system (LMS) in order to virtually provide an effective and meaningful teaching and learning experience. By hosting and integrating an array of digital tools, the LMS has helped to create a complete online classroom; $\mathrm{AoH}$ instructors can post -- in one virtual space -- a module's full lesson components: video, notes, practice assignments, and assessments. In addition, learners are able to upload completed assignments, and instructors are able both to provide feedback and store assessment scores.

And, simultaneously, we fast-tracked the rollout of a new database, ensuring that we had a 
uniform way of tracking attendance and learner information. This also enabled us to provide and virtually house an email address and password for every learner, as well as to sync with the Clever learning platform which allows learners easy access to over ten learning applications and other digital resources used in their classes.

\section{COVID-19 Pandemic: Providing Support to Meet our Learners' Social and Emotional Needs}

While developing the infrastructure to support the academic needs of our learners was timeintensive, stressful, and exhausting for all $\mathrm{AoH}$ staff, providing social and emotional support for learners was even more so for our student support and instructional staff. The COVID-19 crisis has disproportionately impacted the learners we serve, the majority of whom are African-American and living below the poverty-line, exacerbating already existing societal and systemic barriers. In spring 2020, our student support team logged 1,361 contacts with learners after transitioning to remote learning. Support services suddenly included tasks such as assisting learners who suddenly lost housing, as well as helping learners arrange funerals for family members who had died from COVID-19.

As the pandemic spotlights the child safety-net role of K-12 schooling, it also does so for adult literacy education's essential wrap-around services (such as housing support, mental health services, and connection to local and federal resources). Yet, these are the services most difficult to fund. This pandemic-spotlight warrants increased research studies on adult literacy education's broader social mission in order to demonstrate the essentialness of student support services within the narrative of the adult literacy field.

\section{Pandemic Successes}

Despite these intense challenges, we were successful in many ways. Learners who had never turned on a computer prior to the pandemic are now effortlessly Zooming; learners who had never used email are now emailing completed homework assignments to their instructors.

Also, between March 2020 and January 2021while on lockdown -we proudly helped 25 learners earn their high school diploma through the National External Diploma Program (NEDP) and the GED Testing Service. Due to its flexibility as a self-paced online competencybased assessment program, the NEDP proved to be more immediately effective at helping learners earn their high school credential during the onset of the pandemic. However, once the online proctored GED test launched over the summer, our GED-ready learners were able to take advantage of this option.

In addition, our health care workforce program was able to thrive. We designed a successful hybrid model for our newly developed Integrated Education and Training-Based Certified Nursing Assistant (CNA) program (the only CNA program in the District to enroll learners without a high school credential), and learners are just now able to complete the clinical portion of the class as these clinical settings are slowly reopening. In the spring, we are launching a phlebotomy track, which - like our CNA program - will also be based on a hybrid model, allowing us to offer even more health care career pathway options to our learners.

\section{Moving Forward and Tolerating Unknowns as an Adult Literacy Professional}

Although this year was full of challenges, it was also a catalyst for AoH. Academy of Hope has 
long held the goal of offering distance learning for adult students, allowing our programming to better fit the realities of adult learners' busy lives. The pandemic has now forced us to build the infrastructure needed to effectively offer both hybrid and fully remote programs as we move forward.

The year was also full of unknowns, and what we did - and what we are doing - seemed impossible only a year ago, strengthening my resolve to tolerate my own unknowns. As a committed adult literacy practitioner, administrator, and researcher, I have often struggled with the uncertainty of knowing how to balance different adult literacy educational goals, such as the Freirian-inspired goal of providing participatory-literacy education with the goal of preparing learners for high-stakes standardized tests (high-stakes for both learners and programs under WIOA (Roumell et al., 2020). This struggle has often "pulled me up short" (Kerdeman, 2003); as voiced by Branch (2007), I have wrestled with questions: By working to serve individual students, do we suggest the correctness and justness of the institutions and systems that they find themselves in and that we support with our work?" Or, conversely "by working to address the manifest injustices in such a system, do we neglect the individual lives presently caught within it?" (p. xi).

As we slowly move towards a post-pandemic world, I am now more willing to reflect upon these questions, as doing so may better help the field build its capacity to productively host the multiple - and sometimes conflicting - goals of both the adult literacy education field (Demetrion, 2013; Roumell, 2021), as well as of the broader U.S. educational system (Labaree, 1997).
Historically, participation in adult education and workforce programs rises dramatically during economic recessions. According to the National Reporting System, D.C. saw a 25\% increase in adult students between the 2006-2007 and the 2009-2010 school years when the Great Recession occurred. Post-pandemic, it is likely that enrollment in adult literacy programs will also rise as adult learners seek to gain credentials and career training to make them more marketable.

Post-pandemic, a goal of the adult literacy education field should be investing in multileveled Integrated Education and Training (IET) programs to help adult learners achieve their career goals. Simultaneously, however, a post-pandemic goal should also be about helping to ensure that the jobs that IET program participants prepare for have an entry-level family-sustaining wage and lead to meaningful, purposeful careers. In addition, a goal should include serving the needs of all learners, especially those testing at lower ABE-levels, as well as for those not seeking employment.

And, finally, a goal of post-pandemic adult literacy programs should be about facilitating educative spaces "where the potential for an expanded form of learning and the development of new knowledge are heightened" (Gutiérrez, 2008, p.152). This pandemic year, as I immersed myself in learning new technologies, systems, and policies to help quickly orchestrate distance learning, I was reminded of the worth of educative spaces. I remembered the power of such spaces to develop expansive learning, enabling both past and present voices to timelessly connect to one's own, fostering the growth of human potential. Post-pandemic, let this be one of the field's most valuable goals. 


\section{References}

Belzer, A., Leon, T., Patterson, M., Rhodes, C., SalasIsnardi, F., Vanek, J., Webb, C., Wilson-Toro, B. (2020). COVID-19 rapid response report from the field. ProLiteracy. http://www.proliteracy.org/ Resources/Research

Branch, K. (2007). "Eyes on the ought to be": What we teach about when we teach about literacy. Hampton Press.

Demetrion, G. (2013). Conflicting paradigms in adult literacy education: In quest of a US democratic politics of literacy. Routledge.

Gutiérrez, K. D. (2008). Developing a sociocritical literacy in the third space. Reading Research Quarterly, 43(2), 148-164.

Kerdeman, D. (2003). Pulled up short: Challenging selfunderstanding as a focus of teaching and Learning. Journal of Philosophy of Education, 37(2), 293-308.
Labaree, D. F. (1997). Public goods, private goods: The American struggle over educational goals. American Educational Research Journal , 34(1), 39-81.

Roumell, E.A. (2021). Where do we go now? Adult and workforce education policy post-2020. Adult Literacy Education: The International Journal of Literacy, Language, and Numeracy, 3(2), 75-82.

Roumell, E. A., Todoran, C., \& Salajan, F. D. (2020). A Framework for Capacity Building in Adult and Workforce Education Programming. Adult Literacy Education: The International Journal of Literacy, Language, and Numeracy, 2(2), 16-32.

Simpson Baird, A. (2020). The impact of COVID-19 on D.C.'s adult learners: Results from a Spring 2020 survey. DC Policy Center. https://www.dcpolicycenter. org/publications/covid-adult-learners-survey/ 